\title{
PENGEMBANGAN SUMBER DAYA MANUSIA (SDM) TERHADAP TINGKAT ETOS KERJA KARYAWAN PADA HOTEL SANTIKA SUKABUMI
}

\author{
Hendita Yosepa \\ Universitas Muhammadiyah Sukabumi \\ Hendita015@ummi.ac.id \\ Acep Samsudin \\ Universitas Muhammadiyah Sukabumi \\ acepsamsudin@ummi.ac.id \\ Asep Muhamad Ramdan \\ Universitas Muhammadiyah Sukabumi \\ amr37ramdan@ummi.ac.id
}

\begin{abstract}
This study aims to determine the description of Human Resource Development at the level of Employee Work Ethics at Hotel Santika Sukabumi. Data obtained from employees at the Hotel Santika Sukabumi with a population of 54 people. The sampling technique is done by taking the method of saturated sampling, which means sampling based on the existing population. The nature of the research used in this study is to use associative research. Based on research conducted by analyzing the data obtained there is a relationship between Human Resource Development Variables and a positive and significant influence on Employee Work Ethics at Santika Sukabumi Hotel with a value of 3,962, while t table 2,006, so the $t$ value of 3,962> 2,006. The results of the coefficient of determination (R2) Human Resource Development contributed 23.2\% and the rest were influenced by other factors not examined in this study.
\end{abstract}

Keywords: employee performance; human resource development; work ethic.

\section{PENDAHULUAN}

Sumber Daya Manusia (SDM) sebagai salah satu faktor yang sangat penting bahkan tidak dapat dilepaskan dari sebuah perusahaan. Sumber Daya Manusia merupakan asset penting bagi setiap perusahaan, karena menentukan keberhasilan dari perusahaan untuk mencapai tujuan bisnisnya (Dadan Ahmad Fadili, dkk, 2018). Sumber Daya Manusia yang ada dalam perusahaan perlu dikembangkan agar dapat meningkatkan kemampuan kerjanya. Sebuah perusahaan perlu mendorong agar setiap karyawannya bisa meningkatkan kinerjanya supaya keinginan dan tujuan perusahaan cepat tercapai (Meirina, 2011).

Etos kerja salah suatu hal yang sangat penting dalam bekerja karena kesuksesan sebuah perusahaan tergantung dengan etos kerja seorang karyawan (Azizah et al.,2016). Pendapat (Rinaldi, 2016) "Etos kerja seringkali digambarkan sebagai integritas, disiplin, kerja keras, ketekunan dan lain lain". Meningkatkan etos kerja merupakan salah satu bentuk pertanggungjawaban pihak karyawan terhadap perusahaan (Pratana \& Abadi, 2018). Oleh karena itu, setiap individu maupun kelompok diperusahaan harus memiliki etos kerja yang tinggi guna mendukung dalam pencapaian tujuan sebuah perusahaan.

Kegiatan perusahaan untuk meningkatkan kinerja maupun etos kerja dari karyawan adalah salah satunya dengan pengembangan Sumber Daya Manusia. Pengembangan diberikan kepada karyawan meliputi perubahan sikap sehingga karyawan dapat melakukan pekerjaannya lebih efektif. Pengembangan merupakan suatu kegiatan untuk mengembangkan kualitas, meningkatkan penguasaan teori dan keterampilan terhadap persoalan-persoalan yang menyangkut kegiatan perusahaan Upaya ini dilakukan untuk memperbaiki kontribusi produktif pada karyawan dan menghadapi segala kemungkinan yang terjadi akibat perubahan lingkungan. (Anggreni et al., 2019). 
Hendita Yosepa, Acep Samsudin, \& Asep Muhamad Ramdan. Pengembangan Sumber Daya Manusia (SDM) terhadap Tingkat Etos Kerja Karyawan pada Hotel Santika Sukabumi

(Sedarmayanti, 2017) mengatakan Pengembangan Sumber Daya Manusia pada organisasi penting dilaksanakan untuk meningkatkan kinerja maupun etos kerja karyawan, pengembangan yang dilaksanakan secara komprensif akan meningkatkan kinerja para karyawan disuatu perusahaan. Dadan Ahmad Fadili, dkk (2018) menyatakan tujuan dari pengembangan Sumber Daya Manusia yaitu untuk menciptakan karyawan yang memiliki etos kerja yang baik dengan cara meningkatkan kemampuan mereka, selain itu pengembangan Sumber Daya Manusia merupakan hal yang penting dilakukan untuk merubah Sumber Daya Manusia yang dimiliki perusahaan, dari suatu keadaan ke keadaan lain yang lebih baik lagi.

Berdasarkan interview menurut HR Manager Hotel Santika Sukabumi setiap perusahaan akan dituntut untuk terus melakukan pembenahan diberbagai aspek salah satunya dibidang SDM. Salah satu perusahaan yang selalu melakukan pembenahan agar menjadi perusahaan yang lebih baik yaitu Hotel Santika Sukabumi. Berdasarkan data yang dimiliki Hotel ini merupakan hotel yang berada di Pusat Kota Sukabumi tepatnya berada di Jl. Bhayangkara RT 03 RW 01, Sriwidari, Kecamatan Gunungpuyuh Kota Sukabumi. Hotel ini memiliki kamar sebanyak 88 kamar dan karyawan yang berjumlah 54. Hotel Santika Sukabumi merupakan hotel yang sedang bekembang serta selalu berusaha untuk meningkatkan mutu dan kualitas pelayanan yang diberikan kepada para pelanggannya. Sayangnya, terdapat permasalahan pada etos kerja dengan salah satu indikatornya yaitu tingkat kehadiran para karyawan yang tidak konsisten terhadap ketidaktepatan hadir pada tempat mereka bekerja. Etos kerja karyawan menurun dilihat dari tingkat kehadiran karyawan. Dari data perusahaan, diketahui bahwa pada Agustus-September 2019, presentase ketidakhadiran karyawan adalah 5\%. Dari 54 karyawan hotel dan total hari kerja 26 hari sehingga jumlah keseluruhan kehadiran $100 \%$ adalah 1.401 , total kehadiran hanya 1.340 .

Mudiartha dalam (Dikki Mahrizal, 2019) menyatakan rata rata absensi 2-3 persen perbulan masih bisa dinyatakan baik dan absensi lebih dari 3 persen menggambarkan kondisi disiplin kerja yang tidak baik dalam organisasi. Data absensi karyawan Hotel Santika Sukabumi menunjukkan tingkat absensi lebih dari 3 persen dan ini menunjukkan adanya indikasi masalah yang terjadi di dalam Hotel tersebut.

Rendahnya tingkat kehadiran maupun etos kerja karyawan tersebut, mungkin dapat disebabkan oleh beberapa factor, penyusun berasumsi bahwa rendahnya tingkat etos kerja karyawan pada Hotel Santika Sukabumi tersebut secara teoritis belum mencapai kondisi etos kerja yang optimal, kurangnya Pengembangan Sumber Daya Manusia terhadap karyawan Hotel Santika Sukabumi dalam memahami pentingnya etos kerja dalam bekerja, diduga salah satu factor rendahnya tingkat etos kerja karyawan.

Penelitian ini bertujuan menganalisa pengaruh pengembangan SDM terhadap tingkat etos kerja karyawan pada Hotel Santika Sukabumi. Untuk itu penelitian ini diharapkan bermanfaat bagi pihak Hotel.

\section{KAJIAN PUSTAKA DAN PENGEMBANGAN HIPOTESIS}

\section{Pengembangan SDM}

Menurut Sedarmayanti (2017), dengan adanya program pengembangan SDM yang baik, organisasi atau perusahaan akan memiliki kekuatan kompetitif yang lebih berdaya guna dan mampu bersaing secara positif. Sedangkan menurut Kaswan (2016), pengembangan merupakan proses di mana karyawan memperoleh keterampilan dan pengalaman agar berhasil pada pekerjaan sekarang dan tugas tugas di masa yang akan datang. Istilah pengembangan lebih sering digunakan untuk pekerjaan pada level manajerial.

Sedarmayanti (2017) mengemukakan bahwa pengetahuan pegawai harus diperbaiki dan dikembangkan agar mereka tidak berbuat yang merugikan perusahaan atau organisasi dalam pencapaian tujuannya. Pengetahuan dan keterampilan saja belum cukup untuk menjamin suksesnya pencapaian tujuan. Sikap pegawai terhadap pelaksanaan tugas juga merupakan faktor kunci dalam mencapai sukses. Wicaksono (2016) menyatakan bahwa pelaksanaan pengembangan SDM dimaksudkan untuk meningkatkan tingkat etos kerja karyawan agar mau bekerja dengan perilaku 
kerja yang baik sesuai dengan yang dikehendaki oleh perusahaan guna meningkatkan produktivitas kerja perusahaan Apabila etos kerja karyawan tinggi, maka dengan sendirinya akan berpengaruh pada kinerja perusahaan atau organisasi.

Adapun tujuan dari pengembangan seperti yang dijelaskan oleh (Sedarmayanti, 2017) tujuan dalam pengembangan SDM, yaitu sebagai berikut. (1) Produktifitas kerja pegawai akan meningkat, kualitas dan kuantitas produksi semakin baik. (2) Meningkatkan efesiesnsi tenaga, waktu, bahan baku, dan mengurangi ausnya mesin. (3) Mengurangi kerusakan barang, produksi dan mesin karena pegawai semakin ahli dan terampil. (4) Mengurangi tingkat kecelakaan pegawai. (5) Meningkatkan pelayanan kepada pelanggan organisasi karena pemberian pelayanan baik merupakan daya tarik sangat penting. (6) Pegawai akan lebih baik karena keahlian dan keterampilannya sesuai pekerjaannya. (7) Kesempatan untuk meningkatkan karier pegawai semakin besar. (8) Pimpinan semakin cakap dan cepat dalam mengambil keputusan. (9) Kepimpinan seorang pemimpin akan lebih baik. (9) Dengan pengembangan, balas jasa akan lebih diperhatikan. (10) Memberi manfaat baik bagi masyarakat pengguna jasa.

Pengembangan Sumber Daya Manusia menurut Nugraha (2016) dibentuk dari empat dimensi yaitu pendidikan, pengalaman kerja, keterampilan, dan kemampuan teknologi". Sedangkan indikator untuk Pengembangan SDM menurut Krismiyati (2017) terdiri dari tiga indikator, yaitu: Motivasi, Kepribadian, dan Keterampilan.

\section{Etos Kerja}

Secara konseptual etos kerja menurut Anoraga dalam Juni (2017) merupakan "pandangan dan sikap suatu bangsa atau umat terhadap kerja. Apabila individu-individu dalam komunitas memandang kerja sebagai suatu hal yang luhur bagi eksistensi manusia, etos kerjanya cenderung tinggi sebaliknya, jika sikap dan pandangan terhadap kerja sebagai sesuatu yang bernilai rendah bagi kehidupan, etos kerja akan rendah." Sedangkan Menurut Sinamo dalam Juni (2017), "etos kerja adalah seperangkat perilaku positif yang berakar pada keyakinan fundamental yang disertai komitmen total pada paradigma kerja yang integral menurutnya seseorang, perusahaan, atau komunitas yang menganut paradigma kerja, memercayai dan berkomitmen pada paradigma kerja tersebut, akan menunjukan sikap dan perilaku kerja mereka yang khas. Itulah yang menjadi budaya kerja".

Etos kerja yang baik harus dimiliki oleh individu saja, tetapi juga oleh kelompok, bahkan oleh masyarakat secara luas (Kaswan, 2016). The American heritage dictionary of English language (dalam Juni, 2017) menyatakan bahwa etos dapat dipahami dari dua makna berikut. (1) The disposition, character, or attitude peculiar to a specific people, culture or a group that distinguishes it from other peoples or group, fundamental values or spirit, mores. Disposisi, karakterk atau sikap khusus orang, budaya atau kelompok yang membedakannya dari orang atau kelompok lain, nilai atau jiwa yang mendasari adat istiadat. (2) The governing or central principles in a movement, work off art, mode of expression, or the like. Prinsip utama atau pengendalian dalam suatu pergerakan, pekerjaan seni, bentuk ekpresi, atau sejenisnya.

Untuk mengetahui apakah etos kerja atau semangat kerja karyawan di suatu perusahaan itu dalam kondisi tinggi atau rendah dapat dilihat dari dimensi maupun indikatornya. Menurut (Husni, 2014) dimensi etos kerja sebagai berikut. (1) Mempunyai perilaku kerja keras. Seseorang yang memiliki etos kerja akan menunjukkan perilaku bekerja dengan semaksimal mungkin tanpa merasa mengeluh. (2) Disiplin, jujur dan tanggung jawab. Ini dicerminkan dari kebiasaannya ketika mendapatkan tugas dalam pekerjaannya. (3) Rajin dan tekun, dapat dilihat dari kinerjanya ketika menyelesaikan setiap tugas dan tanggung jawab tanpa pantang menyerah sebelum selesai. (4) Menggunakan waktu secara tepat. Dalam menyelesaikan setiap pekerjaan, seseorang yang memiliki etos kerja akan menggunakan waktu dengan sebaik mungkin. Sehingga tidak ada waktu yang terbuang sia- sia ketika menyelesikan suatu pekerjaan. 
Hendita Yosepa, Acep Samsudin, \& Asep Muhamad Ramdan. Pengembangan Sumber Daya Manusia (SDM) terhadap Tingkat Etos Kerja Karyawan pada Hotel Santika Sukabumi

\section{Hipotesis}

H1: Ada pengaruh Pengembangan SDM (X1) terhadap tingkat Etos Kerja karyawan (Y).

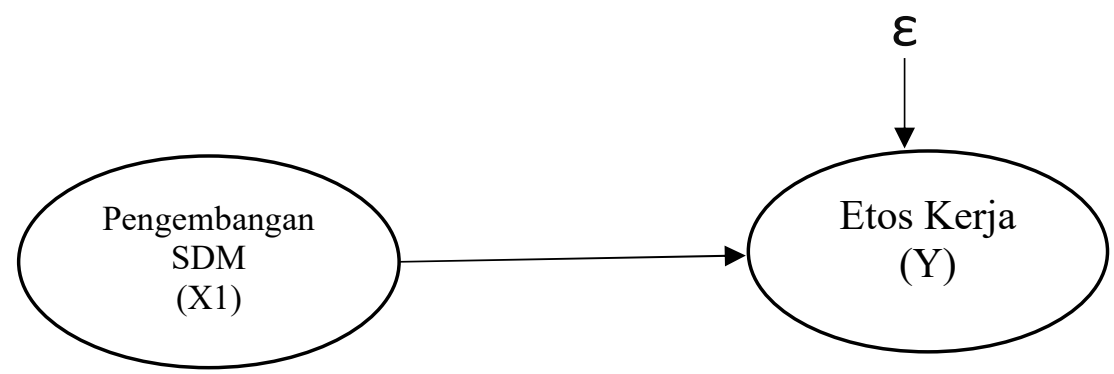

Gambar 1. MODEL PENELITIAN

\section{METODE PENELITIAN}

Penelitian ini adalah kuantitatif. Pengembangan SDM menjadi variabel bebas (X1) sedangkan etos kerja merupakan variable terikat (Y). Sedangkan $\varepsilon$ merupakan variabel lain di luar penelitian. Model penelitian dapat dilihat di Gambar 1. Populasi adalah karyawan Hotel Santika Sukabumi. Populasi pada penelitian ini adalah seluruh karyawan yang berjumlah 54 orang, teknik pengambilan sampel dilakukan dengan metode sampel jenuh, yang berarti pengambilan sampel berdasarkan jumlah populasi yang ada. Metode yang digunakan untuk mengumpulkan data adalah dengan metode survey dengan bantuan kuisioner dengan skala Likert. Pengembangan SDM dan Etos Kerja diukur dengan 8 item. Kuesioner terlebih dahulu diuji validitasnya dengan Pearson product moment correlation, dan reliabilitasnya dengan Cronbach's Alpha menggunakan aplikasi IBM-SPSS Statistics versi 23. Alat analisis yang digunakan adalah regresi linear sederhana.

\section{HASIL DAN PEMBAHASAN}

\section{Uji Validitas}

Tabel 1

HASIL UJI VALIDITAS DATA

\begin{tabular}{ccccc}
\hline No & Item & R Hitung & R Tabel & Keterangan \\
\hline 1 & X1.1 & 0,352 & 0,266 & Valid \\
2 & X1.2 & 0,657 & 0,266 & Valid \\
3 & X1.3 & 0,578 & 0,266 & Valid \\
4 & X1.4 & 0,408 & 0,266 & Valid \\
5 & Y1.1 & 0,640 & 0,266 & Valid \\
6 & Y1.2 & 0,448 & 0,266 & Valid \\
7 & Y1.3 & 0,303 & 0,266 & Valid \\
8 & Y1.4 & 0,691 & 0,266 & Valid \\
\hline
\end{tabular}

Sumber: Output SPPS v23 (2020)

Hasil uji validitas pada tabel 1 menunjukkan bahwa seluruh item pernyataan mengenai variabel $\mathrm{X}$ dan variabel $\mathrm{Y}$, mempunyai nilai $\mathrm{r}$ hitung $>\mathrm{r}$ tabel, dan sesuai dengan ketentuan yang telah ditetapkan, maka hal ini berarti bahwa seluruh item pertanyaan tersebut seluruhnya valid dan dapat digunakan dalam penelitian.

\section{Uji Reliabilitas}

Uji reliabilitas dilihat nilai Cronbach's Alpha sebesar 0,605. Nilai reliabilitas $>0,600$ berarti butir pernyataan dari seluruh variabel seluruhnya reliabel dan dapat digunakan dalam penelitian. 


\section{Uji Regresi Linear Sederhana}

Hasil analisis regresi dari persamaan menunjukkan angka konstan dari unstandardized coeficients sebesar 7,900 yang berarti jika tidak ada Pengembangan SDM (X) maka nilai konsisten dari Etos Kerja (Y) adalah sebesar 7,900. Hasil koefisien regresi diperoleh nilai koefisiensi untuk variabel independen sebesar 0,539. Artinya setiap penambahan 1\% tingkat Pengembangan SDM (X) maka peningkatan Etos Kerja (Y) akan meningkat sebesar 0,539. Karena nilai koefisiensi regresi bernilai positif, Pengembangan SDM (X) berpengaruh positif terhadap Etos Kerja karyawan (Y). Nilai signifikasi menunjukkan bahwa $\mathrm{H} 1$ terbukti dalam penelitian ini.

Tabel 2

HASIL UJI PERSAMAAN REGRESI LINIER SEDERHANA

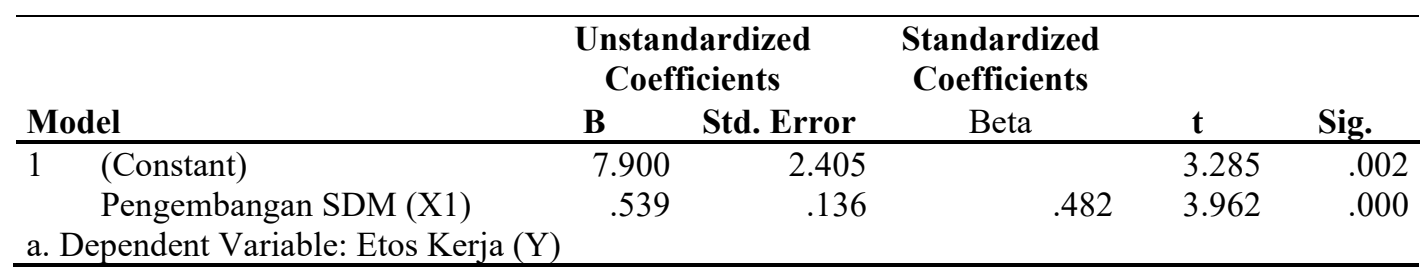

Sumber: Output SPPS v23 (2020)

Table 3

HASIL UJI R ${ }^{2}$

\begin{tabular}{llccc}
\hline Model & $\mathrm{R}$ & R Square & $\begin{array}{c}\text { Adjusted R } \\
\text { Square }\end{array}$ & \multicolumn{2}{c}{$\begin{array}{c}\text { Std. Error of } \\
\text { the Estimate }\end{array}$} \\
\hline 1 & $.482^{\mathrm{a}}$ & .232 & .217 & 1.160 \\
a. Predictors: (Constant), Pengembangan SDM (X1) & \\
\hline \multicolumn{2}{l}{ Sumber: Output SPPS v23 (2020) }
\end{tabular}

Tabel 3 menunjukkan $\mathrm{R}^{2}$ adalah sebesar 0,232 atau sama dengan $23,2 \%$, ini berarti bahwa variable Pengembangan SDM (X) berpengaruh terhadap variable Etos Kerja Karyawan (Y) pada Hotel Santika Sukabumi yaitu sebesar $23,2 \%$ sedangkan sisanya $76,8 \%$ dipengaruhi oleh variabel lain.

\section{Pengaruh Pengembangan SDM terhadap Etos Kerja Karyawan}

Pengembangan sumber daya manusia bertujuan untuk mempersiapkan para karyawan untuk mengikuti perubahan maupun perkembangan globalisasi. Program pengembangan sumber daya manusia yang dilaksanakan pihak Hotel Santika Sukabumi dapat dikatakan baik. Berdasarkan hasil uji hipotesis, diketahui pengaruh pengembangan sumber daya manusia terhadap etos kerja karyawan adalah positif serta signifikan. Hasil penelitian ini mendukung serta sejalan dengan penelitian (Rahayu \& Cahyono, 2018) yang mengungkapkan program pelatihan dan pengembangan sumber daya manusia berpengaruh signifikan terhadap peningkatan etos kerja islami karyawan Bank Syariah Bukopin Surabaya. Terdapat persamaan pada penelitian tersebut menggunakan variable pengembangan sumber daya manusia serta variable independent etos kerja.

Berdasarkan hasil ini dapat dikatakan bahwa semakin baik pengembangan sumber daya manusia yang diberikan maka etos kerja karyawan pada Hotel Santika Sukabumi akan meningkat. Pengembangan sumber daya manusia sangat penting dilakukan untuk mendukung tingkat etos kerja karyawan supaya lebih baik. Selanjutnya hasil uji tersebut di atas dimaknai bahwa upaya intervensi pada variabel Pengembangan sumber daya manusia akan dapat memberikan efek yang lebih besar pada perbaikan tingkat etos kerja karyawan. Hasil regresi variabel pengembangan sumber daya manusia sangat cocok diterapkan untuk memprediksi variabel etos kerja karyawan pada Hotel Santika Sukabumi. Bahwa jika pihak hotel menginginkan etos kerja yang lebih baik maka salah satu upaya intervensi yang paling tepat terlebih dahulu memperbaiki Sumber Daya Manusianya. 
Hendita Yosepa, Acep Samsudin, \& Asep Muhamad Ramdan. Pengembangan Sumber Daya Manusia (SDM) terhadap Tingkat Etos Kerja Karyawan pada Hotel Santika Sukabumi

\section{KESIMPULAN}

Berdasarkan hasil penelitian dan pengujian hipotesis yang telah dilakukan, maka dalam penelitian ini dapat ditarik kesimpulan bahwa Variable Pengembangan Sumber Daya Manusia berpengaruh signifikan terhadap tingkat Etos Kerja Karyawan pada Hotel Santika Sukabumi. Dengan analisis regresi sederhana bernilai positif yang berarti jika Pengembangan Sumber Daya manusia meningkat maka tingkat Etos Kerja Karyawan meningkat. Untuk itu Pengembangan Sumber Daya Manusia pada perusahaan perlu dikelola dengan baik agar terwujudnya keseimbangan antara kemampuan karyawan dengan tuntutan perusahaan. Dengan adanya Pengembangan Sumber Daya Manusia yang semakin baik maka akan memberikan peningkatan terhadap etos kerja karyawan yang lebih baik juga.

Pengembangan Sumber Daya Manusia yang diselenggarakan pihak Hotel sangatlah penting untuk diterapkan. Dengan adanya Pengembangan Sumber Daya Manusia diharapkan para karyawan akan dapat bekerja secara lebih efektif dan efisien dan mempunyai tingkat etos kerja yang tinggi. Untuk menghadapi perubahan yang terjadi seperti perubahan teknologi, perubahan metode kerja, menuntut pula perubahan sikap dan tingkah laku, ketrampilan dan pengetahuan Oleh karena itu pihak Hotel jika ingin berkembang, maka Pengembangan Sumber Daya Manusia terhadap para karyawannya harus mendapatkan perhatian yang besar. Pengembangan Sumber Daya Manusia ini dapat dijadikan referensi dalam kegiatan manajemen sumber daya manusia dalam perencanaan maupun pengorganisasian agar tercapai berbagai tujuan perusahaan. Penelitian selanjutnya dapat melibatkan variabel lain yang berhubungan dengan efektifitas etos kerja karyawan, misalnya kompensasi manajemen atau promosi jabatan sehingga dapat memberikan gambaran yang lebih luas mengenai factor apa saja yang mempengaruhi etos kerja karyawan

\section{DAFTAR PUSTAKA}

Anggreni, P., Suartini, N. W., \& Mahendradatta, U. (2019). STrategi Pengembangan Sumber Daya Manusia Di 3 Perguruan Tinggi Dalam Menghadapi PersaingaN GLOBAL ( Studi pada Universitas di Provinsi Bali ). III(1), 26-34.

Fadili, D. A., Tuhagana, A., \& Jamaludin, A. (2018). Pengaruh Pelatihan Kerja Dan Pengembangan Sumber Daya Manusia Terhadap Kinerja Karyawan. 3(1), 80-85.

Husni, I. (2014). Hubungan Etos Kerja Dengan Kinerja Guru Di Smk Negeri 1 Lubuk Sikaping. Jurnal Bahana Manajemen Pendidikan, 2(1), 341-346. http://ejournal.unp.ac.id/index.php/bahana/article/view/3772/3006

Juni, P. D. (2017). Manajemen Kinerja Kepegawaian Dalam Pengelolaan SUMBER DAYA MANUSIA Perusahaan. CV. Pustaka Setia.

Kaswan. (2016). Pelatihan dan Pengembangan Untuk Meningkatkan Kinerja SUMBER DAYA MANUSIA. Alfabeta.

Krismiyati, K. (2017). Pengembangan Sumber Daya Manusia dalam Meningkatkan Kualitas Pendidikan di SD Negeri Inpres Angkasa Biak. Jurnal Office, 3(1), 43. https://doi.org/10.26858/jo.v3i1.3459

Mahrizal, D. (2019). Jurnal Administrasi dan Perkantoran Modern. 8(3), 28-32. https://jurnal.unimed.ac.id/2012/index.php/judika/index

Meirina, D. T. (2011). Pengembangan Sumber Daya Manusia Dan Produktivitas Kerja Pegawai. Pengembangan Sumber Daya Manusia Dan Produktivitas Kerja Pegawai, 10(19), 15-21. https://doi.org/10.17509/manajerial.v10i2.2161

Nugraha, R. (2016). Pengaruh Pengembangan Sumberdaya Manusia, Disiplin Kerja Dan Lingkungan 
Kerja Terhadap Kinerja Pegawai Pada Inspektorat Kabupaten Morowali. Katalogis, 4(10).

Pegawai, K., Dinas, P., Mikro, U., \& Menengah, K. D. A. N. (n.d.). PROVINSI SULAWESI

TENGGARA THE EFFECT OF WORK ETHICS ON EMPLOYEE PERFORMANCE IN

COOPERATIVE , MICRO , SMALL AND MEDIUM ENTERPRISE OFFICE OF SOUTHEAST SULAWESI PROVINCE. 1-8.

Pratana, A., \& Abadi, F. (2018). Analisis Pengaruh Etos Kerja, Hubungan Kerja Dan Pengembangan Karir Terhadap Komitmen Organisasional Berdampak Pada Kinerja Karyawan. 1(2), 84-92.

RAHAYU, F., \& CAHYONO, H. (2018). Pengaruh Pelatihan Dan Pengembangan Sumber Daya Manusia Terhadap Peningkatann Etos Kerja Islami Karyawan Bank Syariah Bukopin Cabang Darmo Surabaya. Jurnal Ekonomi Islam, 1(2), 38-45.

Rinaldi, M. (2016). Pengaruh Disiplin Kerja Dan Etos Kerja Serta Gaya Kepemimpinan Situasional Terhadap Kinerja Pegawai Di Kantor Badan Penanggulangan Bencana Daerah Kota Palu. Katalogis, 4(10).

Sedarmayanti. (2017a). Perencanaan dan Pengembangan SUMBER DAYA MANUSIA Untuk Meningkatkan Kompetensi, Kinerja, dan Produktivitas Kerja. PT.Refika Aditama.

Sedarmayanti. (2017b). Perencanaan dan Pengembangan SUMBER DAYA MANUSIA Untuk Meningkatkan Kompetensi, Kinerja dan Produkttivitas Kerja (Anna (ed.)). PT. Refika Aditama.

Wicaksono, Y. S. (2016). Pengaruh Pelatihan dan Pengembangan Sumber Daya Manusia dalam Rangka Meningkatkan Semangat Kerja dan Kinerja Karyawan (Studi di SKM Unit V PT. Gudang Garam,Tbk Kediri) Yosep Satrio Wicaksono. Jurnal Bisnis Dan Manajemen, 3(1), 3139. 